\title{
A Brief Overview of Smallholder Farmers' Access to Seed of Improved Legume Varieties
}

For decades, the vast majority of smallholder farmers in developing countries, mainly sub-Saharan Africa (SSA) and to some extent South Asia (SA), heavily rely on non-improved and auto-saved variety seed, accounting for about $80 \%$ of their material used for planting. Though the seed use figures by farmers vary from one region to another, with West Africa showing the lowest rate of improved seed use (below 20\%) and South Asia with much higher rate (up to 70\%), the overall situation looks less encouraging. At the same time, substantial breakthroughs have been made by breeding programs, and many more are still in the pipeline. Some of the traits of recently developed varieties have targeted the consumers' demands and farmers' preferences.

The smallholder farmers' access to the outputs of the breeding programs' achievements has been very weak and hence calls for effective, more coherent, and well-articulated design of technology and seed delivery systems of food legume crops. The Tropical Legumes projects answered this historical call.

The Tropical Legumes projects (TL I, II, and III) are an international research and development initiative under the partnership of the International Crops Research Institute for the Semi-Arid Tropics (ICRISAT), the International Center for Tropical Agriculture (CIAT), the International Institute of Tropical Agriculture (IITA), seven African countries (Burkina Faso, Ghana, Mali, Nigeria, Ethiopia, Tanzania, and Uganda) and one Indian state (Uttar Pradesh), and others. It aimed to develop improved cultivars of common bean, cowpea, chickpea, and groundnut and deliver their seed at scale to millions of smallholders. Since the beginning of Tropical Legumes I (TL I) project in 2007, and the subsequent TL II and TL III projects, a lot has been achieved at different levels of the commodity value chain of each focus crop. The impact can be felt from farmers in remote communities who are now smiling all the way to the banks, to the research centers involved, thanks to this major research and development initiative led by ICRISAT.

This publication covers impact stories from an array of actors within the crop value chain, with a focus on groundnut and common beans in Tanzania and Uganda, groundnut and cowpea in Nigeria, and groundnut in Ghana. All actors were given an 
opportunity to share their perceptions and stories for being part of TL families. These actors involve: National agricultural research institutes; knowledge brokering organizations, e.g., extension services and NGOs; public seed companies; private sector operators, e.g., private seed companies, agro-dealers, and individual seed entrepreneurs; farm implement makers; farmer organizations, e.g., farmer cooperatives, farmer groups, individual farmers, women farmers; and the end-pull investors, e.g., middlemen, processors, traders, and consumers. This document shares records of project achievements through impact stories, testimonies from various value chain actors who benefitted from the TL projects over the past 12 years.

It is our hope that the reader will get inspired reading through great field stories from stakeholders over the 12 years of research and development processes implemented to put smiles on faces of families in farming communities in the dryland areas of focus countries.

Open Access This chapter is licensed under the terms of the Creative Commons Attribution 4.0 International License (http://creativecommons.org/licenses/by/4.0/), which permits use, sharing, adaptation, distribution and reproduction in any medium or format, as long as you give appropriate credit to the original author(s) and the source, provide a link to the Creative Commons licence and indicate if changes were made.

The images or other third party material in this chapter are included in the chapter's Creative Commons licence, unless indicated otherwise in a credit line to the material. If material is not included in the chapter's Creative Commons licence and your intended use is not permitted by statutory regulation or exceeds the permitted use, you will need to obtain permission directly from the copyright holder.

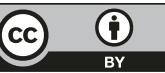

